\title{
A typology of secondary research in Applied Linguistics
}

\begin{abstract}
Secondary research is burgeoning in the field of Applied Linguistics, taking the form of both narrative literature review and especially more systematic research synthesis. Clearly purposed and methodologically sound secondary research contributes to the field because it provides useful and reliable summaries in a given domain, facilitates research dialogues between sub-fields, and reduces redundancies in the published literature. It is important to understand that secondary research is an umbrella term which includes numerous types of literature review. In this commentary, we present a typology of 13 types of well-established and emergent types of secondary research in Applied Linguistics. Employing a four-dimensional analytical framework, focus, review process, structure, and representation of text of the 13 types of secondary research are discussed, supported with examples. This article ends with recommendations for conducting secondary research and calls for further inquiry into field-specific methodology of secondary research.
\end{abstract}

\section{Secondary research in Applied Linguistics: Commentary or research?}

Secondary research, or literature review, refers to a scholarly review of a body of literature on a selected topic (Ellis, 2015). In the field of Applied Linguistics, and elsewhere in the social and natural sciences, there are two main types of secondary research: traditional and systematic (Norris \& Ortega, 2007). Traditional reviews bring together findings on the topic under investigation while providing a connection between the reported research and the macroscopic research terrain. While traditional reviews are often composed in a manner which aims to "tell a story" (Norris \& Ortega, 2006, p. 5), they also tend to include a critique of the literature at hand (an alternative name of some traditional reviews is "critical reviews"). This is especially true in traditional reviews which are published as stand-alone journal articles in which researchers identify strengths and weaknesses of existing studies on a topic. Such reviews usually also make suggestions for future research directions based on the reviewers' expert knowledge and/or based on gaps identified in the literature.

The other main family of secondary research is best characterized by a formal set of methods that are applied to the review process. Such 'systematic reviews', or research syntheses, have gained widespread popularity in Applied Linguistics 
research in recent years, especially those that aggregate quantitative findings. In addition to systematic reviews, a growing body of papers concerning their methodology can also be found (e.g., Li \& Wang, 2018; Macaro, 2020; Norris \& Ortega, 2006; Author 2 et al., 2015a; Author 2 et al., 2015b) and several new contributions are underway (e.g., Author $1 \&$ Author 2, Under Review; Author 2 et al., In Preparation a; Author 2 et al., In Preparation b). Indeed, Norris and Ortega's (2007) prediction that research syntheses "will continue to thrive in our field" (p. 812) has been borne out. Unlike traditional or narrative reviews, systematic research syntheses refer to a "protocol-driven and quality-focused approach" to aggregate research evidence to enlighten theory, research, policy, and practice (Bearman et al., 2012, p. 625).

In parallel to primary research, systematic research syntheses can be broadly divided into two major types: qualitative and quantitative. Qualitative research synthesis, also called "qualitative evidence synthesis" (e.g., Author et al., 2020), assembles qualitative research evidence to "reveal deep insights into disparate literature for future research" (Chen, 2016, p. 387). Another purpose of qualitative research synthesis is to strengthen and deepen qualitative evidence by unraveling "multidimensions, varieties, and complexities" amongst studies (Çiftçi \& Savas, 2017,p. 4).

Quantitative research syntheses, as the name indicates, rely on quantitative data as a means to understand a given domain. The most well-known synthesis of this type is likely meta-analysis, which involves the statistical aggregation of effect sizes across studies (e.g., In'nami et al., 2009). However, a number of other types of quantitative syntheses exist such as scoping reviews and methodological syntheses 
(see below). Figure 1 presents a visual of the basic breakdown of secondary research types introduced thus far.

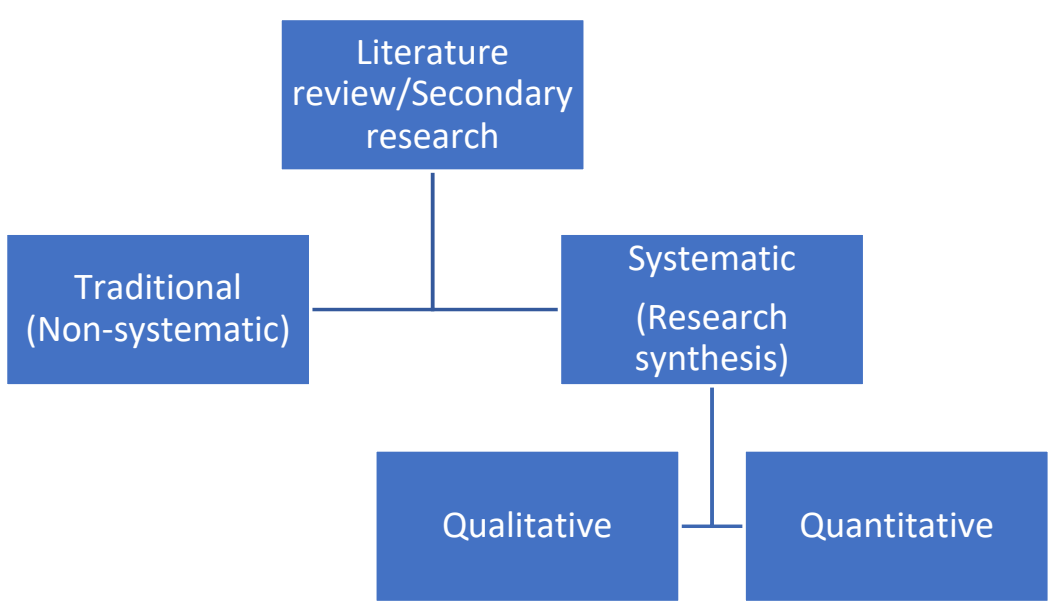

Figure 1. Major types of secondary research

Whilst traditional literature reviews continue to appear in Applied Linguistics journals and other outlets, systematic research syntheses are gaining prominence. Such growth can be attributed to several factors. First, the status of research synthesis has changed in recent years from a kind of "state-of-the-art" think piece or commentary to a valuable form of empirical research necessary to consolidate and advance understanding of a given domain. To be sure, the systematicity, rigor, and transparency associated with research syntheses has greatly diminished the presence of bias and allowed for greater trust to be placed in secondary results. Second, reviews are no longer only produced by senior scholars who offer their authoritative opinions but also by more junior scholars as well as by synthesists working alongside researchers who specialize in the topic of the review (e.g., Author 2 et al., 2019a). Such collaborations between experts in the substantive domain, on one hand, and in synthetic methods on the other, bring a powerful synergy to the task of systematically reviewing a given body of work. A third reason for growth in the prominence of 
research synthesis is its place as "a cornerstone of the evidence-based practice and policy movement" (Dixon-Woods et al., 2007, p. 375) in education, medicine, and many other applied fields. Fourth, systematic research syntheses facilitate “epistemological diversity” (Norris \& Ortega, 2007, p. 813). Through more systematic and comprehensive literature searches (see Author et al., 2015c), systematic research syntheses give voices to research findings published not only in prominent journals (mostly published in English) but also local and regional journals as well as other less-visible but valuable sources such as master's and doctoral theses.

Despite the growth and prominence of secondary research, we have noticed a lack of consistency in naming conventions in the synthetic literature. More importantly, underlying this inconsistency appears to be a misunderstanding of the different approaches to synthesis and their corresponding techniques and goals.

Consequently, we see an urgent need to clarify not only the labels but the characteristics and accepted norms for conducting systematic research syntheses in Applied Linguistics.

\section{A typology of secondary research in Applied Linguistics}

In the previous section, we have established that secondary research in Applied Linguistics has experienced a shift from the narrative tradition to a more systematic, empirical approach. While the development of systematic research synthesis is gaining momentum, it is unlikely that traditional literature reviews will be replaced entirely. Rather, in our view, it benefits the whole research field that the two families of secondary research co-exist, serving different purposes to advance our understanding. With this in mind, and to provide structure and guidance to future 
synthetic efforts, we address in the remainder of this paper the following question: "What are the different types of secondary research in Applied Linguistics?"

A number of taxonomies or typologies have been proposed to standardize conventions and practices of secondary research, for example, in healthcare (Grant \& Booth, 2009), health sciences (Littell, 2018), medical sciences (Munn et al., 2018), and social sciences (Cooper, 1988). With the proliferation of secondary research in Applied Linguistics in recent years, we believe the development of a field-specific typology is necessary. At the outset, however, a few disclaimers are warranted. Firstly, this typology is not a result of a comprehensive and fully systematic literature search, although considerations were given as to what reviews to include as examples in the typology (see below). Second, given the nature of this article (which is a commentary), analysis of the included reviews will indubitably represent, to a certain extent, our own views, biases, and experiences as primary and secondary/synthetic researchers. Third, this typology is not to be seen as conclusive or definitive. Because of the dynamic development of secondary research in Applied Linguistics, we regard this typology as a work in progress and invite contributions and revisions which build on it. Finally, the purpose of presenting this preliminary typology is not to prescribe best practices in secondary research. Rather, we hope but to offer an overview of this versatile and emergent set of methodological techniques as a means to standardize some of the naming and methodological conventions being employed. We also seek to expose the field to some of the potential approaches to and outcomes of secondary research that might otherwise be unfamiliar or overlooked.

In the remainder of this article, we discuss features of 13 types of secondary research in Applied Linguistics. Discussions on relevant features are based on the frameworks by Gough et al. (2012) and Grant and Booth (2009). The features 
analyzed include purpose of review, process of review (search strategy, appraisal mechanism, synthesis techniques, analysis techniques), and product of review (i.e., structure and representation of text) (Figure 2). Features of each type of secondary research will first be discussed (Table 1). Then, the 13 types of secondary research will be compared to identify issues and suggest a way forward. It must be emphasized that the types of literature review/secondary research above are by no means mutually exclusive. It is common, in fact, for secondary studies to overlap (e.g., Author 2 et al., 2011 is a methodological synthesis and a meta-analysis; Tullock \& Ortega, 2017 is a scoping review and a meta-analysis).

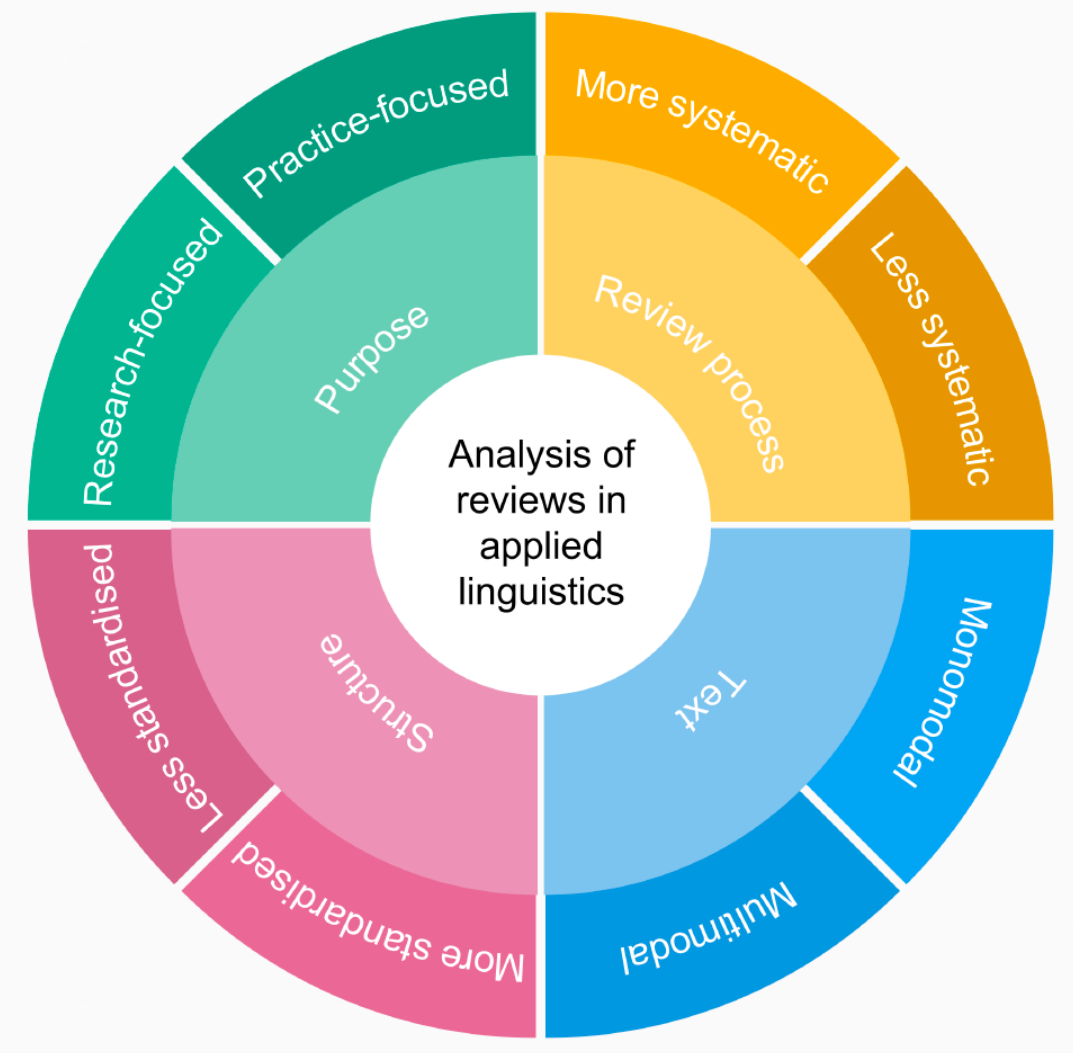

Figure 2: Four areas for analyzing secondary research in Applied Linguistics 
1) Critical review: The purpose of a critical review is to explore prevalent views in a research topic and offer alternative perspectives. Muñoz and Singleton (2011), for instance, reviews and challenges the prevalent view of maturational constraints toward second language acquisition. Moreover, this type of review often discusses key questions within the target domain. Lai and Li (2011) provide another example in their critical review on the intersection of technologies and task-based language teaching. Regarding the review process, there is generally no explicit description of how literature included in the review was searched and appraised, nor does it mention how the findings from existing research are synthesized and analyzed. The text of a critical review of literature takes a narrative approach, discussing prevalent issues thematically, with arguments or views illustrated by individual studies. In terms of product, a critical review often has a customized structure with headings related to the specific prevalent issues. Unlike the majority of the secondary research types, information in a critical review is usually represented using words but not figures or tables.

2) Meta-analysis: Meta-analysis is one of the most prominent types of systematic research synthesis in Applied Linguistics (Author 2, 2014). It aims to consolidate similarities and clarify conflicting findings. Given its quantitative nature, synthesists who conduct meta-analysis are often interested in effects or efficacy of a particular intervention. For example, Kang and Han's (2015) meta-analysis quantified the overall effects of written corrective feedback on improving linguistic accuracy of second language writers; as is typical in meta-analysis, the study also identified a number of factors which moderate the effect of written corrective feedback. The review process of meta-analysis is documented in detail, 
usually in a separate "method" section, with sub-sections dedicated to the literature search, coding process, and analysis. The two meta-analyses included in Table 1 reported how data were synthesized through coding of the features of primary studies and how the reliability of the coding was upheld (e.g., Author 2 et al. 2019b). The synthesized data were then analyzed using descriptive and inferential statistics to estimate and identify effect sizes, outliers, publication bias, and moderators. The procedures involved in reliability generalization metaanalysis are quite, a sub-type of meta-analysis, the procedures are nearly identical to meta-analysis. However, the focus is on aggregating estimates of measurement error (see, e.g., Author 2, 2016; Author 2, 2019). As a type of systematic research synthesis, meta-analysis follows a rather standard structure like a primary study, usually with additional materials included as supplementary online documents (e.g., coding scheme of Author 2 et al. (2019b) is made available on IRIS). In addition to words, meta-analysis utilizes figures, tables, and bullet points to document the review procedure and make the otherwise information-dense piece more reader-friendly.

3) Methodological synthesis: This type of research synthesis can take two different approaches. Some focus on assessing the methodological approaches, designs, tools, and so forth within a given substantive domain, as in Author 2 et al.'s (2011) review of interactionist research in SLA. Other methodological syntheses take as their defining principle a particular research technique or tool. This approach can be seen, for example, in Author 2 et al.'s (2018b) review of selfpaced reading tasks. Concerning the review process, the two reviews included in Table 1 represent a similarly systematic approach (Author 2 et al., 2016; Crowther et al., 2021). Similar to meta-analysis, Author 2 et al. (2016) documented the 
coding process and how reliability of coding was maintained. In relation to how data were analyzed, the calculated percentages and frequencies of different research and reporting practices. These data are used to describe and evaluate the methods in the domain in question as well as to provide empirically-grounded recommendations for future research. Like other types of research synthesis, the structure of a methodological synthesis is highly standardized.

4) Mixed review: As the name suggests, this type of research synthesis is a combination of two types of review. For example, Jackson and Suethanapornkul (2013) is a combination of a qualitative research synthesis and meta-analysis on task complexity whilst Marsden et al.'s (2018) extensive work is a presentation of a narrative and systematic literature review on replication studies in second language research. The review process, textual structure, and representation vary and are contingent on the types of reviews included. For instance, Jackson and Suethanapornkul (2013) follows a systematic approach to research synthesis with explicit description of how the included literature was searched, selected, extracted, and synthesized. As for structure, two approaches are noted. In Jackson and Suethanapornkul (2013), a convergent approach was adopted by presenting the qualitative research synthesis and meta-analysis as one single review, with the findings of each complementing each other (like the convergent design of mixedmethods studies noted in Creswell and Clark, 2017). Another structural approach is sequential, meaning that one review is presented at a time (e.g., a narrative review is first presented in Marsden et al., 2018 and then the systematic literature review). When there are two reviews in a given report (sequential), the first is usually broader with the second one being based on a subset of the first (e.g., Yan et al.'s review and meta-analysis of elicited imitation). Because of the profound 
breadth and depth of the work (e.g., Marsden et al., 2018 is 71 pages long), mixed reviews often include additional online materials.

5) Narrative review: This research-focused review aims to map the "state of the art" in a given domain. Often written by leaders in a particular domain, the objective of this type of review is "to authoritatively answer particular research questions, and to identify gaps in research methodologies" (Norris \& Ortega, 2006, p. 4). Referring to the two included narrative reviews in Table 1, there seems to be divergence in terms of how the review process is enacted. In DeKeyser and Botana (2015), a narrative review is presented in the form of a traditional research synthesis with a customised structure addressing various facets of the research topic of L2 grammar acquisition. On the contrary, Thomson and Derwing (2015) adopt a more systematic approach, which is exemplified from the brief section on how studies were appraised and how findings of the included studies were analysed by calculating percentages. (We would note, however, that Thomson and Derwing's choice to include this information is atypical of this type of review.) Both reviews include individual studies as examples of points of interest to substantiate their arguments. However, neither of these narrative reviews explicate their search strategy or synthesis procedure. It appears that both reviews adopt a thematic approach (as reflected from the section headings) despite not stating how these themes are generated. In terms of structure, sections similar to a typical primary study are found in Thomson and Derwing (2015) whilst a thematicallydriven organization is found in DeKeyser and Botana (2015). Usually only textual representation is found in these narrative reviews.

6) Qualitative research synthesis: This type of systematic research synthesis is dedicated to the aggregation of qualitative research evidence, usually in 
classroom-based studies, to unravel complexities of ecological and naturalistic research studies. Author et al. (2020) for example, synthesises students' and teachers' perception of technology-mediated task-based language teaching based on 16 studies. Like other types of systematic research synthesis such as metaanalysis, qualitative research synthesis strictly follows a systematic procedure of searching and selecting relevant literature. Because of its qualitative nature, much attention is paid to ensure "openness" in the data coding process to fully capture emerging themes. Both Chen (2016) and Author et al. (2020) adopt the constant comparison method of grounded theory to perform initial, focused, and axial coding of data (Charmaz, 2014). Unlike meta-analysis, however, reliability of coding of qualitative research synthesis is usually achieved through multiple rounds of discussions between reviewers. As for its structure, qualitative research synthesis follows the standard structure of a research paper, with important textual information underscored using diagrammatical and tabular representations.

7) Research agenda: The purpose of a research agenda is to "discuss research tasks" (Svalberg, 2012, p. 376) and "review existing studies... to summarize current knowledge and to identify research gaps" (Lou \& Noels, 2019, p. 1). Similar to the aforementioned types of traditional literature reviews, authors of a research agenda do not specify the methods used to search and screen relevant studies. As far as analysis of literature is concerned, at least two forms can be employed. First, as illustrated in Svalberg (2012), the reviewed literature is presented narratively and thematically. In each theme, the reviewer offers an overview statement or argument which is supplemented with a few studies as examples. Each section concludes with research tasks which spring from the limitations of the reviewed studies. Another approach is the one adopted in Lou and Noels 
(2019) which focuses on an emerging research field, mindsets in language teaching and learning. In their research agenda, the authors first offer a review of the current research base in a thematically threaded fashion, analogous to Svalberg's (2012) approach. Nevertheless, instead of adding research tasks at the end of each thematic section, Lou and Noels (2019) examine the way forward in a separate conclusion section. Regardless of the approaches, a research agenda is usually structured thematically with section headings. Sometimes, crucial information is presented in tabular form to enhance clarity and impact (e.g., the construct of engagement with language in Svalberg, 2012).

8) Research into practice: The objective of this type of research synthesis is selfexplanatory. Being a specific type of review of the journal Language Teaching, a "research into practice" review resembles a narrative review but with a more practical focus, that is, the application of research findings in language classrooms. For instance, Lee (2013) and Graham (2017) examine aspects of research on written corrective feedback and listening strategies which are overapplied and under-applied in classrooms. As a type of traditional research synthesis, there is no mention of how the topical literature was collected and assessed. Taking a thematic approach to analyze literature, pedagogically-related topics are examined by citing individual studies, and in some cases, with the addition of personal experience (e.g., Graham, 2017). A "research into practice" synthesis adopts a customized structure presented in textual form.

9) Scoping review: Taking a systematic and inclusive approach, a scoping review aims to map the research landscape of a given domain (Pham et al., 2014). Adhering to its systematic nature, the review process is conducted in a structured manner and each step in the process is reported extensively to maintain 
transparency, objectivity, and credibility (e.g., the inclusion and exclusion

criteria). The included research is coded and measures are in place to ascertain inter-coder reliability (e.g., through coder training in Author 2 et al., 2019a). As for the analysis of coded research, synthesists conducting a scoping review usually present the overview of a research base by calculating frequencies and percentages. Depth of analysis is maintained through the discussion of individual studies of interest (Tullock \& Ortega, 2017). Because of its systematic nature, scoping reviews are structured as a standardized research paper, with texts being accompanied with tables and figures. Finally, although scoping reviews tend to appear as 'stand-alone' pieces, they can also serve to identify specific subdomains ripe for further inquiry via meta-analysis.

10) State-of-the-art review: State-of-the-art reviews are usually a more exhaustive and comprehensive review of a specific research topic. For example, the journal Language Teaching requires authors of state-of-the-art reviews to include approximately 100 works in the bibliography (Language Teaching, 2020). Ultimately, the mission of this kind of research synthesis is to "point out contradictions and omissions - as well as - agreement" in the field (Language Teaching, 2020). In the two examples, methods pertaining to the literature search and selection are explicitly mentioned in one (Hanks, 2019) but not the other (Bardovi-Harlig and Stringer, 2010). As for data analysis, a more personal approach is adopted to offer an insider's perspective. For example, "a dialogic approach" between the author and other researchers is adopted in Hanks (2019) and a thematic approach is adopted in Bardovi-Harlig and Stringer (2010). In both cases, the analysis of the literature is done through the provision of overview statements, followed by substantiation with a number of studies as examples. 
Being more extensive (these two examples are each 45 pages long), a state-of-theart review often relies on tables and figures in addition to narrative exposition (see Bardovi-Harlig \& Comajoan-Colomé, 2020 for an example which is published as a dedicated article type called "State of the Scholarship" in Studies in Second Language Acquisition).

11) Systematic literature review: A systematic literature review (also called 'research synthesis') can be practice-focused or research-focused. Practiceoriented systematic literature reviews provide arguments in favor of a practice (Author et al., 2018) and evaluate issues pertaining to enactment of such practice (Macaro et al., 2018). As for research-focused systematic literature reviews, their aim is to assess the quality and range of studies and provide an updated literature search to inform new research questions (Macaro et al., 2018). Literature search strategies are devised and selection of literature is carefully planned and executed. The included literature is coded by multiple reviewers and reliability of coding is emphasized. "Data" are analyzed using thematic analysis and, like other types of systematic reviews, by calculating frequencies and percentages to observe patterns and trends in the sample. In many ways, a systematic literature review can be seen as overlapping with meta-analysis is all respects except for the aggregation of effect sizes. A typical research paper structure is adopted, with texts supplemented with figures and tables.

12) Historical review: The review types discussed thus far generally treat their target domains as a whole or perhaps in different groupings based on features or variables shared across certain studies. By contrast, historical reviews use time as an organizing principle and as a means to understand the theoretical and/or methodological development that has taken place in a given domain. Boo, 
Dörnyei, and Ryan (2015), for example, traced the recent history of L2 motivation research, focusing on changes in theoretical models, research designs, and target languages, among other features. The authors describe their methods in details and followed procedures much like those of other systematic review types, presenting results in tables and figures to aid in clarity. Historical reviews can also, however, take the form of a timeline. The journal Language Teaching has published many reviews of this type. Timelines generally begin with a broad introduction to situate the domain in question and to highlight major themes and/or developments that have taken place. Landmark publications and other pertinent events are then presented chronologically, usually accompanied by annotations as well as thematic indicators presented in the introduction. See Isaacs and Harding's (2017) timeline of pronunciation assessment in L2 research as a prime example of this type of synthesis.

13) Bibliometric review: As in other types of reviews, bibliometric analyses focus on the study/report as unit of analysis. However, the focus here is on publication meta-data such as citation counts, (co-)citation within and across publications, authorship attributes (e.g., number, gender, language and geographic background), article titles and keywords, and so forth. Bibliometric research is fairly new to Applied Linguistics, but it appears to be surging. Hyland and Jiang (2019), for example, analyzed the frequency as well as linguistic and stylistic features of citation patterns both over time and across four disciplines including applied linguistics. (For another recent bibliometric analysis of citation patterns, see Lei \& Liu, 2018.) Aryadoust and Ang (in press) take on a narrower domain, that of eyetracking research in the language sciences. Using a sample of 341 publications, the authors extract and analyze citations and co-citations as well as research 
affiliations and countries, among other types of publication meta-data. The authors' co-citation analysis found a number of prominent "clusters" of scholarly activity and influence. As in other quantitative and systematic review types, bibliometric analyses often utilize tables and figures to present their findings. 
Table 1: A typology of research synthesis in applied linguistics

\begin{tabular}{|c|c|c|c|c|c|c|c|c|c|}
\hline \multirow{2}{*}{ Type of review } & \multicolumn{3}{|l|}{ Example } & \multirow{2}{*}{ Purpose } & \multicolumn{4}{|l|}{ Process } & \multirow{2}{*}{ Product } \\
\hline & Author & Topic & Journal & & Search & Appraisal & Synthesis & Analysis & \\
\hline \multirow[b]{2}{*}{ Critical review } & Lai and $\operatorname{Li}(2011)$ & $\begin{array}{l}\text { Technology and task- } \\
\text { based language } \\
\text { teaching }\end{array}$ & CALICO Journal & \multirow{2}{*}{$\begin{array}{l}\text { - To explore common } \\
\text { views and offer } \\
\text { alternative } \\
\text { perspectives } \\
\text { To discuss key } \\
\text { questions in a research } \\
\text { area }\end{array}$} & \multirow[t]{2}{*}{ Not stated } & \multirow[t]{2}{*}{ Not stated } & \multirow[t]{2}{*}{ Not stated } & \multirow{2}{*}{$\begin{array}{l}\text { - A narrative, } \\
\text { thematic approach } \\
\text { - Views supported by } \\
\text { individual studies }\end{array}$} & \multirow{2}{*}{$\begin{array}{l}\text { - A customised } \\
\text { structure } \\
\text { - Textual } \\
\text { representation }\end{array}$} \\
\hline & $\begin{array}{l}\text { Muñoz and } \\
\text { Singleton (2011) }\end{array}$ & $\begin{array}{l}\text { Critical period in } \\
\text { second language } \\
\text { acquisition }\end{array}$ & Language Teaching & & & & & & \\
\hline \multirow[b]{2}{*}{ Meta-analysis } & $\begin{array}{l}\text { Kang and Han } \\
(2015)\end{array}$ & $\begin{array}{l}\text { Written corrective } \\
\text { feedback }\end{array}$ & $\begin{array}{l}\text { The Modern } \\
\text { Language Journal }\end{array}$ & \multirow{2}{*}{$\begin{array}{l}\text { - To consolidate } \\
\text { similarities and } \\
\text { explain contradictory } \\
\text { findings } \\
\text { - To examine effect and } \\
\text { efficacy }\end{array}$} & \multirow[t]{2}{*}{$\begin{array}{l}\text { Explicitly } \\
\text { stated }\end{array}$} & \multirow[t]{2}{*}{$\begin{array}{l}\text { Explicitly } \\
\text { stated }\end{array}$} & \multirow{2}{*}{$\begin{array}{l}\text { - Data are } \\
\text { coded } \\
\text { - Reliability of } \\
\text { coding } \\
\text { addressed }\end{array}$} & \multirow[t]{2}{*}{$\begin{array}{l}\text { Inferential statistical } \\
\text { tests }\end{array}$} & \multirow{2}{*}{$\begin{array}{l}\text { - A standard structure } \\
\text { of a primary study } \\
\text { (with supplementary } \\
\text { online materials) } \\
\text { - Textual } \\
\text { representation } \\
\text { together with figures, } \\
\text { tables, and bullet } \\
\text { points }\end{array}$} \\
\hline & $\begin{array}{l}\text { Author } 2 \text { et al. } \\
\text { (2019b) }\end{array}$ & $\begin{array}{l}\text { Second language } \\
\text { anxiety }\end{array}$ & $\begin{array}{l}\text { Studies in Second } \\
\text { Language } \\
\text { Acquisition }\end{array}$ & & & & & & \\
\hline \multirow[b]{2}{*}{$\begin{array}{l}\text { Methodological } \\
\text { review }\end{array}$} & $\begin{array}{l}\text { Crowther et al., } \\
2021\end{array}$ & Cluster analysis & Language Learning & \multirow{2}{*}{$\begin{array}{l}\text { - To assess } \\
\text { methodological } \\
\text { approaches and tools } \\
\text { used to research a } \\
\text { particular topic } \\
\text { - To address } \\
\text { methodological issues }\end{array}$} & $\begin{array}{l}\text { Explicitly } \\
\text { stated }\end{array}$ & $\begin{array}{l}\text { Explicitly } \\
\text { stated }\end{array}$ & Explicitly stated & $\begin{array}{l}\text { - Calculate } \\
\text { percentages and } \\
\text { frequencies } \\
\end{array}$ & \multirow{2}{*}{$\begin{array}{l}\text { - A standard structure } \\
\text { of a primary study } \\
\text { - Textual } \\
\text { representation } \\
\text { together with figures, } \\
\text { and tables }\end{array}$} \\
\hline & $\begin{array}{l}\text { Author } 2 \text { et al. } \\
\text { (2016) }\end{array}$ & $\begin{array}{l}\text { Task-based language } \\
\text { teaching }\end{array}$ & $\begin{array}{l}\text { Annual Review of } \\
\text { Applied Linguistics }\end{array}$ & & $\begin{array}{l}\text { Explicitly } \\
\text { stated }\end{array}$ & $\begin{array}{l}\text { Explicitly } \\
\text { stated }\end{array}$ & $\begin{array}{l}\text { - Data are } \\
\text { coded } \\
\text { - Reliability of } \\
\text { coding } \\
\text { addressed }\end{array}$ & $\begin{array}{l}\text { - Calculate } \\
\text { percentages and } \\
\text { frequencies } \\
\text { - Calculate means } \\
\text { and standard } \\
\text { deviation } \\
\end{array}$ & \\
\hline \multirow{2}{*}{ Mixed review } & $\begin{array}{l}\text { Jackson \& } \\
\text { Suethanapornkul } \\
\text { (2013) }\end{array}$ & $\begin{array}{l}\text { Second language task } \\
\text { complexity }\end{array}$ & Language Learning & \multirow[t]{2}{*}{$\begin{array}{l}\text { Dependent on the types } \\
\text { of research synthesis }\end{array}$} & \multirow{2}{*}{$\begin{array}{l}\text { Dependent } \\
\text { on the types } \\
\text { of research } \\
\text { synthesis }\end{array}$} & \multirow{2}{*}{$\begin{array}{l}\text { Dependent } \\
\text { on the types } \\
\text { of research } \\
\text { synthesis }\end{array}$} & \multirow{2}{*}{$\begin{array}{l}\text { Dependent on } \\
\text { the types of } \\
\text { research } \\
\text { synthesis }\end{array}$} & \multirow[t]{2}{*}{$\begin{array}{l}\text { Dependent on the } \\
\text { types of research } \\
\text { synthesis }\end{array}$} & \multirow{2}{*}{$\begin{array}{l}\text { - A convergent } \\
\text { approach } \\
\text { - A sequential } \\
\text { approach } \\
\text { - With supplementary } \\
\text { online materials } \\
\end{array}$} \\
\hline & $\begin{array}{l}\text { Marsden et al. } \\
\text { (2018) }\end{array}$ & $\begin{array}{l}\text { Replication of second } \\
\text { language research }\end{array}$ & Language Learning & & & & & & \\
\hline \multirow{3}{*}{ Narrative review } & $\begin{array}{l}\text { DeKeyser \& } \\
\text { Botana (2015) }\end{array}$ & $\begin{array}{l}\text { L2 grammar } \\
\text { acquisition }\end{array}$ & Applied Linguistics & \multirow{2}{*}{$\begin{array}{l}\text { To map the rapid } \\
\text { development of a field } \\
\text { (often written by } \\
\text { leaders of the field) } \\
\text { - To identify research } \\
\text { gaps }\end{array}$} & Not stated & Not stated & Not stated & $\begin{array}{l}\text { - A narrative, } \\
\text { thematic approach } \\
\text { Support views with } \\
\text { individual studies } \\
\end{array}$ & $\begin{array}{l}\text { - A customised } \\
\text { structure } \\
\text { - Textual } \\
\text { representation only } \\
\end{array}$ \\
\hline & $\begin{array}{l}\text { Thomson \& } \\
\text { Derwing (2015) }\end{array}$ & $\begin{array}{l}\text { L2 pronunciation } \\
\text { instruction }\end{array}$ & Applied Linguistics & & $\begin{array}{l}\text { Explicitly } \\
\text { stated }\end{array}$ & $\begin{array}{l}\text { Explicitly } \\
\text { stated }\end{array}$ & Not stated & $\begin{array}{l}\text { - } \text { Calculate } \\
\text { percentages } \\
\text { - Support views with } \\
\text { individual studies } \\
\end{array}$ & $\begin{array}{l}\text { - A standard structure } \\
\text { of a primary study } \\
\text { - Textual } \\
\text { representation only }\end{array}$ \\
\hline & Chen (2016) & $\begin{array}{l}\text { Technology-mediated } \\
\text { peer feedback }\end{array}$ & $\begin{array}{l}\text { Computer Assisted } \\
\text { Language Learning }\end{array}$ & & $\begin{array}{l}\text { Explicitly } \\
\text { stated }\end{array}$ & $\begin{array}{l}\text { Explicitly } \\
\text { stated }\end{array}$ & & & \\
\hline
\end{tabular}




\begin{tabular}{|c|c|c|c|c|c|c|c|c|c|}
\hline $\begin{array}{l}\text { Qualitative } \\
\text { research } \\
\text { synthesis }\end{array}$ & $\begin{array}{l}\text { Author } 1 \text { et al. } \\
(2020)\end{array}$ & $\begin{array}{l}\text { Technology-mediated } \\
\text { task-based language } \\
\text { teaching }\end{array}$ & $\begin{array}{l}\text { Language Learning } \\
\& \text { Technology }\end{array}$ & $\begin{array}{l}\text { - To aggregate } \\
\text { qualitative research } \\
\text { evidence } \\
\text { - To reveal complexities } \\
\text { in findings with high } \\
\text { ecological validity }\end{array}$ & & & $\begin{array}{l}\text { - Data are } \\
\text { coded } \\
\text { - Reliability of } \\
\text { coding } \\
\text { addressed }\end{array}$ & $\begin{array}{l}\text { Grounded theory } \\
\text { adopted to ensure } \\
\text { "openness" in coding }\end{array}$ & $\begin{array}{l}\text { - A standard structure } \\
\text { of a primary study } \\
\text { - Textual } \\
\text { representation with } \\
\text { figures, tables }\end{array}$ \\
\hline \multirow{2}{*}{ Research agenda } & Svalberg (2012) & Language awareness & Language Teaching & \multirow[t]{2}{*}{$\begin{array}{l}\text { To summarise current } \\
\text { literature base } \\
\text { - To propose research } \\
\text { tasks }\end{array}$} & \multirow[t]{2}{*}{ Not stated } & \multirow[t]{2}{*}{ Not stated } & \multirow[t]{2}{*}{ Not stated } & $\begin{array}{l}\text { - A narrative, } \\
\text { thematic approach } \\
\text { Research tasks } \\
\text { suggested by the } \\
\text { end of each theme }\end{array}$ & \multirow[t]{2}{*}{$\begin{array}{l}\text { - A customised } \\
\text { structure } \\
\text { - Textual } \\
\text { representation with } \\
\text { tables }\end{array}$} \\
\hline & $\begin{array}{l}\text { Lou \& Noels } \\
(2019)\end{array}$ & $\begin{array}{l}\text { Mindsets in language } \\
\text { education }\end{array}$ & System & & & & & $\begin{array}{l}\text { - A narrative, } \\
\text { thematic approach } \\
\text { Research tasks } \\
\text { suggested at the end } \\
\text { of the review }\end{array}$ & \\
\hline \multirow[b]{2}{*}{$\begin{array}{l}\text { Research into } \\
\text { practice }\end{array}$} & Graham (2017) & Listening strategies & Language Teaching & \multirow{2}{*}{$\begin{array}{l}\text { To review research } \\
\text { findings (not) applied in } \\
\text { language classrooms }\end{array}$} & \multirow[t]{2}{*}{ Not stated } & \multirow[t]{2}{*}{ Not stated } & \multirow[t]{2}{*}{ Not stated } & - A narrative, & \multirow{2}{*}{$\begin{array}{l}\text { - A customised } \\
\text { structure } \\
\text { - Textual } \\
\text { representation }\end{array}$} \\
\hline & Lee (2013) & $\begin{array}{l}\text { Written corrective } \\
\text { feedback }\end{array}$ & Language Teaching & & & & & $\begin{array}{l}\text { thematic approach } \\
\text { - Support views with } \\
\text { individual studies } \\
\text { (and personal } \\
\text { experience) }\end{array}$ & \\
\hline \multirow[b]{2}{*}{ Scoping review } & $\begin{array}{l}\text { Author } 2 \text { et al. } \\
(2019 a)\end{array}$ & Heritage language & $\begin{array}{l}\text { International Journal } \\
\text { of Bilingualism }\end{array}$ & \multirow{2}{*}{$\begin{array}{l}\text { To survey the landscape } \\
\text { and boundary of } \\
\text { emerging fields }\end{array}$} & \multirow[t]{2}{*}{$\begin{array}{l}\text { Explicitly } \\
\text { stated }\end{array}$} & \multirow[t]{2}{*}{$\begin{array}{l}\text { Explicitly } \\
\text { stated }\end{array}$} & \multirow{2}{*}{\begin{tabular}{|l|} 
- \\
Data are \\
coded \\
- Reliability of \\
coding \\
addressed \\
\end{tabular}} & \multirow{2}{*}{$\begin{array}{l}\text { - Calculate } \\
\text { percentages } \\
\text { - Support views with } \\
\text { individual studies }\end{array}$} & \multirow{2}{*}{$\begin{array}{l}\text { - A standard structure } \\
\text { of a primary study } \\
\text { - Textual } \\
\text { representation with } \\
\text { figures, tables }\end{array}$} \\
\hline & $\begin{array}{l}\text { Tullock \& Ortega } \\
\text { (2017) }\end{array}$ & Study abroad & System & & & & & & \\
\hline \multirow{2}{*}{$\begin{array}{l}\text { State-of-the-art } \\
\text { review }\end{array}$} & $\begin{array}{l}\text { Bardovi-Harlig } \\
\text { and Stringer } \\
(2010)\end{array}$ & Language attrition & $\begin{array}{l}\text { Studies in Second } \\
\text { Language } \\
\text { Acquisition }\end{array}$ & \multirow[t]{2}{*}{$\begin{array}{l}\text { To identify patterns and } \\
\text { gaps in a research field } \\
\text { through an exhaustive } \\
\text { survey }\end{array}$} & $\begin{array}{l}\text { Explicitly } \\
\text { stated }\end{array}$ & $\begin{array}{l}\text { Explicitly } \\
\text { stated }\end{array}$ & \multirow[t]{2}{*}{ Not stated } & \multirow[t]{2}{*}{$\begin{array}{l}\text { - A (personal), } \\
\text { narrative, thematic } \\
\text { approach } \\
\text { - Support views with } \\
\text { individual studies }\end{array}$} & $\begin{array}{l}\text { - A customised } \\
\text { structure } \\
\text { - Textual } \\
\text { representation with } \\
\text { figures, tables } \\
\end{array}$ \\
\hline & Hanks (2019) & Exploratory practice & Language Teaching & & Not stated & Not stated & & & $\begin{array}{l}\text { - A standard structure } \\
\text { of a primary study } \\
\text { - Textual } \\
\text { representation with } \\
\text { figures, tables }\end{array}$ \\
\hline & $\begin{array}{l}\text { Author } 2 \text { et al. } \\
(2018)\end{array}$ & Course grades & $\begin{array}{l}\text { Foreign Language } \\
\text { Annals }\end{array}$ & \multirow{2}{*}{\begin{tabular}{|l|} 
- To provide empirical \\
support for \\
pedagogical practices \\
- To evaluate \\
implementation issues \\
of practices \\
- To evaluate quality \\
and range of studies of \\
a particular topic \\
\end{tabular}} & \multirow[t]{2}{*}{$\begin{array}{l}\text { Explicitly } \\
\text { stated }\end{array}$} & \multirow[t]{2}{*}{$\begin{array}{l}\text { Explicitly } \\
\text { stated }\end{array}$} & \multirow{2}{*}{$\begin{array}{l}\text { - Data are } \\
\text { coded } \\
\text { - Reliability of } \\
\text { coding } \\
\text { addressed }\end{array}$} & \multirow{2}{*}{$\begin{array}{l}\text { - Conduct thematic } \\
\text { analysis } \\
\text { - Calculate } \\
\text { frequencies and } \\
\text { percentages } \\
\text { - Support views with } \\
\text { individual studies }\end{array}$} & \multirow{2}{*}{$\begin{array}{l}\text { - A standard structure } \\
\text { of a primary study } \\
\text { (with supplementary } \\
\text { online materials) } \\
\text { - Textual } \\
\text { representation } \\
\text { together with figures, } \\
\text { tables, and bullet } \\
\text { points }\end{array}$} \\
\hline $\begin{array}{l}\text { Systematic } \\
\text { literature review }\end{array}$ & $\begin{array}{l}\text { Macaro et al. } \\
(2018)\end{array}$ & $\begin{array}{l}\text { English medium } \\
\text { instruction }\end{array}$ & Language Teaching & & & & & & \\
\hline
\end{tabular}




\begin{tabular}{|c|c|c|c|c|c|c|c|c|c|}
\hline \multirow[t]{2}{*}{$\begin{array}{l}\text { Historical } \\
\text { review }\end{array}$} & Boo et al. (2015) & $\begin{array}{l}\text { L2 motivation } \\
\text { research }\end{array}$ & System & $\begin{array}{l}\text { Explore theoretical and } \\
\text { methodological } \\
\text { developments over time }\end{array}$ & $\begin{array}{l}\text { Explicitly } \\
\text { stated }\end{array}$ & $\begin{array}{l}\text { Explicitly } \\
\text { stated }\end{array}$ & Explicitly stated & Explicitly stated & $\begin{array}{l}\text { - A standard structure } \\
\text { of a primary study } \\
\text { - Textual } \\
\text { representation with } \\
\text { figures, tables }\end{array}$ \\
\hline & $\begin{array}{l}\text { Isaacs \& Harding } \\
(2017)\end{array}$ & $\begin{array}{l}\text { L2 pronunciation } \\
\text { assessment }\end{array}$ & Language Teaching & $\begin{array}{l}\text { Mark milestones and } \\
\text { trace the history of } \\
\text { research on L2 } \\
\text { pronunciation assessment }\end{array}$ & Not stated & Not stated & Not stated & Not stated & $\begin{array}{l}\text { Introduction plus } \\
\text { chronological } \\
\text { presentation of } \\
\text { landmark publications } \\
\text { events with annotation }\end{array}$ \\
\hline \multirow[t]{2}{*}{$\begin{array}{l}\text { Bibliometric } \\
\text { review }\end{array}$} & $\begin{array}{l}\text { Hyland \& Jiang } \\
(2019)\end{array}$ & Citation patterns & Applied Linguistics & $\begin{array}{l}\text { Frequency, patterns, and } \\
\text { associated linguistic } \\
\text { features of citation over } \\
\text { time and across } \\
\text { disciplines }\end{array}$ & $\begin{array}{l}\text { Explicitly } \\
\text { stated }\end{array}$ & $\begin{array}{l}\text { Explicitly } \\
\text { stated }\end{array}$ & Explicitly stated & Explicitly stated & $\begin{array}{l}\text { - A standard structure } \\
\text { of a primary study } \\
\text { - Textual } \\
\text { representation with } \\
\text { figures, tables } \\
\end{array}$ \\
\hline & $\begin{array}{l}\text { Aryadoust \& Ang } \\
\text { (in press) }\end{array}$ & $\begin{array}{l}\text { Eye-tracking in the } \\
\text { language sciences }\end{array}$ & $\begin{array}{l}\text { Computer-Assisted } \\
\text { Language Learning }\end{array}$ & $\begin{array}{l}\text { To identify citation and } \\
\text { publication clusters and } \\
\text { patterns of influence }\end{array}$ & $\begin{array}{l}\text { Explicitly } \\
\text { stated }\end{array}$ & $\begin{array}{l}\text { Explicitly } \\
\text { stated }\end{array}$ & Explicitly stated & Explicitly stated & $\begin{array}{l}\text { - A standard structure } \\
\text { of a primary study } \\
\text { - Textual } \\
\text { representation with } \\
\text { figures, tables } \\
\end{array}$ \\
\hline
\end{tabular}




\section{Four continua of research synthesis in Applied Linguistics}

Having laid out the 13 types of secondary research being employed in Applied Linguistics, we now turn to four dimensions or continua that characterize and distinguish between them. These include (a) research vs. practice; (b) more vs. less systematic; (c) more vs. less structured presentation; and (d) multi- vs. mono-modal.

The "research-vs. practice-focused" continuum

Unsurprisingly, the objective of the majority of the secondary research types is research-oriented. Purely research-focused reviews can be used to summarize the current state of research or aggregate research evidence (e.g., state-of-the-art review), to explore emerging research areas (e.g., scoping review), to challenge mainstream perspectives (e.g., critical review), to address methodological issues in research (e.g., methodological synthesis), to suggest new research directions (e.g., research agenda). On the other hand, two types of secondary research, systematic literature review and qualitative research synthesis, can address both research- and practice-related issues. For instance, in their qualitative research synthesis, Author 1 et al. (2020) draw implications from the synthesized research evidence to inform technology-mediated task-based language teaching research and practice. As for systematic literature reviews, Author 2 et al. (2018) address and express caution around the use of course grades as metrics to assess language proficiency levels in classrooms and in L2 research. Amongst the 13 types of secondary research identified above, there is only one type which focuses exclusively on pedagogical practices: research into practice. "Research into practice" reviews concern the extent to which findings from classroom-based studies are applicable to in authentic educational contexts. In 
particular, reviewers are interested in underscoring areas of research findings which are under-, over-, and possibly mis-applied.

There is a unequal focus of secondary work in Applied Linguistics on research. Currently, there is a dearth of reviews which focus on practice, as exemplified from the fact that "research into practice" reviews can only be found with regularity in one journal (Language Teaching). While it is the primary purpose of secondary research to target researchers, it is meaningful to explore review types which focus primarily on informing the practice of language teaching and learning (Author 1, 2020). In addition to evaluating the success of knowledge transfer from academia to the professional context, practice-focused secondary research can focus on synthesizing data from naturalistic, classroom-based studies to showcase evidencebased practices. Moreover, it is important for synthesists to specify the purpose of their reviews. The connection between the purported goal of the reviews and the review process should be stated explicitly. "Meta-review", or "reviews of reviews" can be conducted to examine the alignment between heterogeneity (or the lack thereof) of objectives in each type of secondary research. Moreover, investigations can be carried out on the (mis)alignment between the purpose of research syntheses and their review processes.

\section{The "more systematic vs. less systematic" continuum}

Regarding systematicity of the review process, the reviewed examples show that there is an even distribution of the 13 types of research synthesis on the continuum. Five types of secondary research adopt a systematic approach and traditional approach to reviewing, respectively (meta-analysis, systematic literature review, qualitative research synthesis, scoping review, methodological review). 
Moreover, three (mixed review, narrative review, state-of-the-art review) utilize a mixture of systematic and narrative review strategies. Research syntheses which embrace the more systematic review process include a discrete "methodology" section detailing the various stages of the review process namely literature search strategy, inclusion and exclusion criteria, a coding scheme for data extraction/collection, and data analysis. To reduce bias and increase credibility, these systematic research syntheses are transparent with their coding procedure, often sharing their coding scheme as supplementary materials or appendices (e.g., Chen, 2016), calculating inter-coder reliability (e.g., Author 2 et al., 2019a; see Norouzian, in press), and describing strategies to resolve disagreement in the synthesis and analysis stage (e.g., resolving disagreement through discussions in Author 1 et al., 2020). By contrast, the three types of traditional secondary research (critical review, research into practice, research agenda), tend to employ a less systematic process. Resembling the "commentary" style of secondary research, these research syntheses do not explicate how the review process is conducted nor do they provide justifications for the adoption of a particular review protocol.

Based on the typology in Table 1, another observation is the ambiguity of the review processes of some types of secondary research. With regards to the aforementioned examples, mixed review, narrative review, and state-of-the-art review do not demonstrate a consistent take on the systematicity of the process. While we can understand that the systematicity of mixed reviews is contingent on the mixture of the review types, it raises concerns regarding the stark contrast in the methods used in the paired examples of the other two review types. Without a consensual view towards review methodology, we are likely to encounter challenges for researchers who want to conduct such kinds of review. It is imperative to conduct comprehensive reviews 
on the methodologies used in each type of secondary research and the variation thereof. It would be fruitful to review methodologies of (a) earlier and more recent secondary research; (b) secondary research published in top-tiered and less prestigious journals/outlets, (3) written by researchers at various career stages, and (4) published in different sub-domains of Applied Linguistics. Despite being a strenuous task, such work would yield valuable insights into the differentiation between "ideal", “acceptable", and "unacceptable" review protocols of each type of secondary research. (For an example of an evaluation of meta-analytic techniques in applied linguistics, see Author 2 et al., 2016).

Secondly, three types of secondary research adopt a less systematic review process (critical review, research agenda, research into practice), relying mainly on the authors' expertise and judgement to identify important themes and studies as examples. The majority of these reviews do not include an explanation of how themes are generated or how studies are chosen. Although credibility of these reviews may not be an issue because they are usually written by leading scholars in the field to offer an "authoritative stance", it is important to minimize bias by providing a brief statement on the reflective process of the reviewers. Hanks (2019) is a commendable example in this respect. In her review which adopts a "dialogic approach", Hank makes clear that the review process is rigorous despite not having "a third-party stance" (p. 145). She acknowledges her personal stance and explains how her perspectives are co-constructed through interactions with researchers, professionals, and doctoral students.

The "more standardized structure vs. less standardized structure" continuum 
From a genre analysis perspective, some secondary research types adhere to a more standardized structure while structures of others are more idiosyncratic. The kinds of secondary research which follow a more standardized reporting structure are also those which implement a more systematic review protocol, including metaanalysis, systematic literature review, qualitative research synthesis, methodological synthesis, bibliometric review, and scoping review. Their standardized organizational approach comprises six structural moves: introduction, background literature, method, findings, discussion, implications/conclusion, in parallel to a typical primary research paper. These types of research synthesis often include additional online supplementary information such as coding schemes and bibliographical summaries of the synthesized studies. On the other hand, secondary research which adopt a less standardized structure are those which employ a less systematic and rigorous review procedure (i.e., critical review, research into practice, research agenda). These types of secondary research, which narrate the synthesized findings through a thematic approach, organize the review text based on prominent themes. An interesting observation emanating from this comparison is found in the two examples of narrative review. Traditionally, narrative review is viewed as a type of secondary research which relies on a less systematic synthesis process; nevertheless, one narrative review above follows a primary research paper structure (Thomson \& Derwing, 2015), while the other uses a customized thematic structure (DeKeyser \& Botana, 2015). This case, which demonstrates a lack of consensus of a preferred structure for narrative reviews, is made even more intriguing when these two reviews were published in the same journal (i.e., Applied Linguistics). While the discussion of only two examples makes it impossible to draw any definitive conclusion, it suggests that the two teams of reviewers may have different perceptions or conceptualizations towards "narrative 
review", with Thomson and Derwing (2015) leaning more towards the "synthesis as research" side while DeKeyser and Botana (2015) regard narrative review as an "authoritative commentary".

They major takeaway which pertains to structural organization of secondary research is quite apparent: Reviews which adopt a more systematic and scientific review protocol are represented in a more standardized structure while those which are written in a "commentary" style are more flexible with their structures. From the typology, the only type of secondary research which shows disagreement in terms of structural approach is narrative review. To further understand structural variations of each type of secondary research, genre analysis can be conducted to identify the "cognitive structuring" (Garzone, 2015, p. 6) or "schematic structure of the discourse" (Swales, 1990, p. 58) used to convey communicative purposes in each research synthesis type.

The "multimodal text vs. monomodal text" continuum

Referring to the analytical framework (Figure 2), the representation of the review text is another dimension of variation across review types. Over half of the secondary research types adopt multimodal representation, using a combination of text, figures, and tables. Among these types of secondary research, six (meta-analysis, systematic literature review, qualitative research synthesis, scoping review, methodological synthesis, bibliometric review) adopt systematic review protocols. To present large sums of information in a clear and systematic manner, these reviews utilize tables and figures to document the steps of review and collate bibliographical, substantive, and methodological information from the selected studies (e.g., Chen, 2016). By contrast, the four types of text which generally rely on monomodal text 
(i.e., narrative review, critical review, research into practice, research agenda)

represent the types of secondary research which follow a more flexible mechanism of review.

Similar to the previous continuum, the decision on whether to utilize different modes to present secondary results seems to be associated with the systematicity of the review. For more systematic types of reviews, figures and tables are usually used to present methodological flow and underscore synthesized findings. Bullet points are sometimes used to list out factual information (e.g., the list of journals consulted, the list of search terms used, inclusion/exclusion criteria). Future research on secondary research practices might look into "science of using science", which refers to the study of "the efficacy of interventions applied to increase decision-makers' use of research in various decision arenas" (Langer, Tripney, Gough, 2016, p. 1). One form of intervention to enhance evidence-informed decision making which can be investigated is the mode of presentation of synthesized research evidence (e.g., the use of infographical representation of synthesized findings to facilitate use of research findings by practitioners).

\section{Conclusion}

This article provides an overview of the common types of secondary research in the field of Applied Linguistics (see Table 2 for a summary). The main objective of this piece is to demonstrate the distinctiveness (or the lack thereof) among types of secondary research through four perspectives: topic (research/practice focus), review process (systematic/traditional), structure (standardized/customized), and representation of text (textual/multimodal). The typology presented will be useful to not only novice reviewers (e.g., postgraduate students) as a primer but also seasoned 
synthesists to explore different secondary research orientations and options. Most importantly, we hope that this typology can serve as a catalyst to facilitate discussions on secondary and synthetic research methodologies and ultimately, lead to the formulation of methodological guidelines for each type of secondary research for our own field.

Table 2: A summary of the 13 types of secondary research in Applied Linguistics

\begin{tabular}{|c|c|c|c|c|}
\hline Review type & Research Focus & Systematic & $\begin{array}{c}\text { Standardized } \\
\text { structure }\end{array}$ & Multimodal \\
\hline Critical review & + & - & - & - \\
\hline Meta-analysis & + & + & + & + \\
\hline $\begin{array}{l}\text { Methodological } \\
\text { review }\end{array}$ & + & + & + & + \\
\hline Mixed review & + & $+/-$ & $+/-$ & $+/-$ \\
\hline Narrative review & + & $+/-$ & $+/-$ & - \\
\hline $\begin{array}{l}\text { Qualitative } \\
\text { research } \\
\text { synthesis }\end{array}$ & $+/-$ & + & + & + \\
\hline Research agenda & + & - & - & + \\
\hline $\begin{array}{l}\text { Research into } \\
\text { practice }\end{array}$ & - & - & - & - \\
\hline Scoping review & + & + & + & + \\
\hline $\begin{array}{l}\text { State-of-the-art } \\
\text { review }\end{array}$ & + & $+/-$ & $+/-$ & + \\
\hline $\begin{array}{l}\text { Systematic } \\
\text { literature review }\end{array}$ & $+/-$ & + & + & + \\
\hline Historical review & $+/-$ & $+/-$ & $+/-$ & $+/-$ \\
\hline
\end{tabular}




\begin{tabular}{|l|l|l|l|l|}
\hline $\begin{array}{l}\text { Bibliometric } \\
\text { review }\end{array}$ & + & + & + & + \\
\hline
\end{tabular}

\section{References}

Aryadoust, V., \& Ang, B. H. in press. 'Exploring the frontiers of eye tracking research in language studies: a novel scientometric review,' Computer Assisted Language Learning.

Author 1, A. 2020.

Author 1, A., et al. 2020.

Author 2, A., et al., 2011.

Author 2, A. 2014.

Author 2, A., et al. 2015a.

Author 2, A., et al. 2015b.

Author 2, A., et al. 2015c.

Author 2, A., et al. 2016.

Author 2, A., et al. 2018a.

Author 2, A., et al. 2018b.

Author 2, A., et al., 2019a.

Author 2, A., et al. 2019b.

Author 1, A., \& Author 2, A. Under Review.

Author 2, A., et al. In Preparation a.

Author 2, A., et al., In Preparation b.

Bardovi-Harlig, K., \& Comajoan-Colomé, L. 2020. 'The aspect hypotheses and the acquisition of L2 past morphology in the last 20 years,' Studies in Second Language Acquisition 1-31.

Bardovi-Harlig, K., \& Stringer, D. 2010. 'Variables in second language attrition: 
Advancing the state of the art,' Studies in Second Language Acquisition 32: 145.

Bearman, M., Smith, C. D., Carbone, A., Slade, S., Baik, C., Hughes-Warrington, M., \& Neumann, D. L. 2012. 'Systematic review methodology in higher education,' Higher Education Research \& Development 31/5: 625-640.

Boo, Z., Dörnyei, Z., \& Ryan, S. (2015). L2 motivation research 2005e2014:

Understanding a publication surge and a changing landscape. System, 55, 145157.

Charmaz, K. 2006 Constructing Grounded Theory (2 $2^{\text {nd }}$ ed.). Sage.

Chen, T. 2016. 'Technology-supported peer feedback in ESL/EFL writing classes: A research synthesis,' Computer Assisted Language Learning 29/2: 365-397.

Çiftçi, Y., \& Savas, P. 2017. 'The role of telecollaboration in language and intercultural learning: A synthesis of studies published between 2010 and 2015,'ReCALL 30/3: 278-298.

Cooper, H. M. 1988. 'Organizing knowledge synthesis: A taxonomy of literature reviews,' Knowledge in Society 1: 104-26.

Creswell, J. W., Clark, V. L. P. 2017. Designing and Conducting Mixed Methods Research ( $3^{\text {rd }}$ ed.). Sage.

Crowther, D., Kim, S., Lee, J., Lim, J., \& Loewen, S. 2021. 'Methodological synthesis of cluster analysis in second language research,' Language Learning 71: 99-130.

DeKeyser, R., \& Botana, G. P. 2015. 'The effectiveness of processing instruction in L2 grammar acquisition: A narrative review,' Applied Linguistics 36/3: 290305.

Dixon-Woods, M., Sutton, A., Shaw, R., Miller, T., Smith, J., Young, B., Bonas, S., 
Booth, A., \& Jones, D. 2007. 'Appraising qualitative research for inclusion in systematic reviews: A quantitative and qualitative comparison of three methods,' Journal of Health Services Research \& Policy 12/1: 42-47.

Ellis, R. 2015. 'Introduction: Complementarity in research syntheses,' Applied Linguistics 36/3: 285-289.

Garzone, G. E. 2015. Genre analysis in Tracy, K., Ilie, C., \& Sandel, T. (eds.): The international encyclopaedia of language and social interaction. Wiley.

Gough, D., Thomas, J., \& Oliver, S. 2012. 'Clarifying differences between review designs and methods,' Systematic Reviews 1: 28.

Graham, S. 2017. Research into practice: Listening strategies in an instructed classroom setting,' Language Teaching 50/1: 107-119.

Grant, M. J., \& Booth, A. 2009. 'A typology of reviews: An analysis of 14 review types and associated methodologies,' Health Information and Libraries Journal 26: 91-108.

Hanks, J. 2019. 'From research-as-practice to exploratory practice-as-research in language teaching and beyond,' Language Teaching 52: 143-187.

Hyland, K., \& Jiang, F. 2019. 'Points of reference: Changing patterns of academic citation,' Applied Linguistics 40: 64-85.

In'nami, Y., \& Koizumi, R. 2009. 'A meta-analysis of test format effects on reading and listening test performance: Focus on multiple-choice and open-ended formats,' Language Testing 26/2: 219-244.

Isaacs, T., \& Harding, L. (2017). Pronunciation assessment. Language Teaching, 50, $347-366$.

Jackson, D. O., \& Suethanoapornkul, S. 2013. 'The cognition hypothesis: A synthesis 
and meta-analysis of research on second language task complexity,' Language Learning 63/2: 330-367.

Kang, E., \& Han, Z. 2015. 'The efficacy of written corrective feedback in improving L2 written accuracy: A meta-analysis,' The Modern Language Journal 99/1: $1-18$.

Lai, C., \& Li, G. 2011. 'Technology and task-based language teaching: A critical review,' CALICO Journal 28/2: 498-521.

Language Teaching. 2020. Instructions for Authors. Cambridge University Press. https://www.cambridge.org/core/journals/languageteaching/information/instructions-contributors

Laurenz, L., Tripney, J., \& Gough, D. 2016. The Science of Using Science: Researching the Use of Research Evidence in Decision-Making. University College London. https://www.alliance4usefulevidence.org/assets/Science-ofUsing-Science-Final-Report-2016.pdf

Lee, I. 2013. 'Research into practice: Written corrective feedback,' Language Teaching 46/1: 108-119

Lei, L., \& Liu, D. 2018. Research trends in applied linguistics from 2005 to 2016: A bibliometric analysis and its implications,' Applied Linguistics 40: 540-561.

Li, S., \& Wang, H. 2018. 'Traditional literature review and research synthesis' in A. Phakiti, A., De Costa, P., \& Plonsky, L., \& Starfield, S. (eds.): Palgrave handbook of applied linguistics research methodology. Palgrave.

Littell, J. H. 2018. 'Conceptual and practical classification of research reviews and other evidence synthesis products,' Campbell Systematic Reviews 14/1: 1-21. Lou, N. M., \& Noels, K. A. 2019. 'Promoting growth in foreign and second language 
education: A research agenda for mindsets in language learning and teaching,' System 86/November: 102126.

Macaro, E., Curle, S., Pun, J., An, J., \& Dearden, J. 2018. 'A systematic review of English medium instruction in higher education,' Language Teaching 51/1: $36-76$.

Macaro, E. 2020. 'Systematic reviews in applied linguistics' in McKinley, J. \& Rose, H. (eds): The Routledge handbook of research methods in applied linguistics. Routledge.

Marsden, E., Morgan-Short, K., Thompson, S., \& Abugaber, D. 2018. 'Replication in second language research: Narrative and systematic reviews and recommendations for the field,' Language Learning 68/2: 321-391.

Munn, Z., Stern, C., Aromataris, E., Lockwood, C., \& Jordan, Z. 2018. 'What kind of systematic review should I conduct? A proposed typology and guidance for systematic reviewers in the medical and health sciences,'. BMC Medical Research Methodology 18.

Muñoz, C., \& Singleton, D. 2011. 'A critical review of age-related research on L2 ultimate attainment,' Language Teaching 44/1: 1-35.

Nikolov, M., \& Djigunović, J. M. 2011. 'All shades of every color: An overview of early teaching and learning of foreign languages,' Annual Review of Applied Linguistics 31/March: 95-119.

Norris, J. M., \& Ortega, L. 2006. Synthesizing Research on Language Learning and Teaching. John Benjamins Publishing Company.

Norris, J. M., \& Ortega, L. 2007. 'The future of research synthesis in applied linguistics: Beyond art or science,' TESOL Quarterly 41/4: 805-815.

Norouzian, R. in press. 'Inter-rater reliability in second language meta-analyses: The 
case of categorical moderators,' Studies in Second Language Acquisition.

Pham, M. T., Rajić, A., Greig, J. D., Sargeant, J. M., Papadopoulos, A., \& McEwen, S. A. 2014. 'A scoping review of scoping reviews: Advancing the approach and enhancing consistency,' Research Synthesis Methods 5/4: 371-385.

Swales, J. 1990. Genre Analysis. Cambridge University Press.

Svalberg, A. M.-L. 2012. 'Language awareness in language learning and teaching: A research agenda,' Language Teaching 45/3: 376-388.

Thomson, R. I., \& Derwing, T. M. 2015. 'The effectiveness of L2 pronunciation instruction: A narrative review,' Applied Linguistics 36/3: 326-344.

Tullock, B., \& Ortega, L. 2017. 'Fluency and multilingualism in study abroad: Lessons from a scoping review,' System 71/December: 7-21.

Vorobel, O., \& Kim, D. 2012. 'Language teaching at a distance: An overview of research,' CALICO Journal 29/3: 548-562.

Yan, X., Maeda, Y., Lv, J., \& Ginther, A. 2015. 'Elicited imitation as a measure of second language proficiency: A narrative review and meta-analysis,' Language Testing 33/4: 497-528. 